\title{
PERFIL DE DISPENSAÇÃO DE ANTIMICROBIANOS ANTES E DEPOIS DA PROMULGAÇÃO DA RDC 44/2010
}

\author{
Rondinelli de Carvalho LADEIRA, William Espinato Pimentel de MORAES, Cristiano Guilherme Alves de \\ OLIVEIRA, Sérgio Henrique de Mattos MACHADO \& Juliano Gomes BARRETO
}

Universidade Iguaçu, Campus V. Itaperuna, Rio de Janeiro, Brasil.

*Autor para correspondência: rondinellicl@uol.com.br

DOI: http://dx.doi.org/10.18571/acbm.139

\section{RESUMO}

O trabalho foi elaborado por meio de uma pesquisa prospectiva com base em dados obtidos em uma farmácia comunitária do estado de Rio de Janeiro, no período de 28 de outubro de 2009 a 29 de outubro de 2012, ano que antecedeu a promulgação da RDC 44/2010 e os dois anos subsequentes à promulgação. Objetivando-se a avaliar o perfil de dispensação de antimicrobianos nos períodos que precederam e sucederam a RDC 44/2010. Constatou-se que as dispensações desses medicamentos diminuíram, chegando a um déficit de $56,78 \%$ para a cefalexina nos anos analisados.

Palavras-chave: Automedicação; Retenção de receita; Resistência bacteriana.

\begin{abstract}
The paper was done by means of a retrospective study based on data obtained in a community pharmacy in the state of Rio de Janeiro, during the period of October 28, 2009, and October 29, 2012 , in the year preceding the promulgation of RDC 44/2010 and the two years following the promulgation. Aiming to evaluate the antimicrobial dispensing profile in the periods that preceded and succeeded RDC 44/2010. It was found that the dispensation of these drugs drecreased, reaching a deficit of $56.78 \%$ for cephalexin in the years analyzed.
\end{abstract}

Keywords: Self-medication; Prescription retention; Bacterial resistance.

\section{Introdução}

O advento dos antibióticos no final da década de 20 revolucionou a ciência e trouxe a medicina para a era moderna. Pela primeira vez fomos capazes de combater e vencer bactérias causadoras de diversas infecções, a principal causa de mortalidade à época (TAVARES, 2009).

Considere-se antibiótico toda a substância capaz de matar ou inibir o crescimento de bactérias. Para ser efetivo e tolerável o antibiótico precisa ser uma substância nociva às bactérias, mas relativamente segura para as nossas células. Isso não significa que não possa haver efeitos secundários, mas por definição, um antibiótico deve ser muito mais tóxico para germes invasores do que para o organismo invadido (BRITO, CORDEIRO, 2012).

As bactérias são seres com capacidade de desenvolver evoluções para que assim possam habitar qualquer local na atualidade, tanto em condições amenas ou até mesmo extremas, nesse caso, como forma primária de resistência a antibióticos pode-se citar o alto poder de mutação e a recombinação dos genes, no qual há possibilidade de serem transmitidos futuramente durante a reprodução da bactéria, de uma bactéria mutável e outra não mutável, desta forma favorecendo o surgimento e o aumento dos tipos de bactérias geneticamente modificadas. Atualmente existe outra forma de resistência, em que há o uso abusivo e indiscriminado dos antibióticos, seja por automedicação ou por indicação médica, criando um ambiente extremamente favorável ao 
surgimento de bactérias resistentes. Este problema afeta tanto a saúde individual como a coletiva, sendo uma real preocupação para os que lidam com a saúde pública, todavia, pode-se afirmar que, hoje, as bactérias são resistentes a ação da maioria dos antibióticos existentes (TAVARES, 2009).

No sentido de combater possíveis resistências advindas do uso indiscriminado de antibióticos, a Agência Nacional de Vigilância Sanitária (ANVISA) instituiu em 26 de outubro de 2010 a Resolução de Diretoria Colegiada (RDC) 44, que dispõe sobre o controle de antimicrobianos, com o objetivo de diminuir a resistência microbiana que tem como uma das causas o uso abusivo de antibióticos. De acordo com a norma, as farmácias devem condicionar a dispensação de medicamentos à apresentação e à retenção da primeira via da receita de controle especial (CRF-MT, 2010).

Além disso, a RDC 44/2010 estabelece um prazo de dez dias para a validade da receita e determina que as farmácias armazenem os dados do paciente e de quem recebeu a orientação quanto ao uso. Essa medida representa muito mais que o simples controle da venda de antibióticos. Ela devolve às mãos do farmacêutico o processo de orientação quanto ao uso correto deste tipo de medicamento (BRASIL, 2010).

O objetivo dessa pesquisa é avaliar quais as classes de antimicrobianos estavam sendo dispensadas o período, se havia dispensação de antibióticos sem a devida retenção da receita, avaliando assim se a legislação estava sendo cumprida. Essa pesquisa foi realizada levando-se em consideração os períodos de um ano que antecederam a RDC 44/2010 e os dois anos que a procederam.

Nesse intuito foi realizado um estudo retrospectivo quantitativo e documental através de análise de prescrições de fármacos antimicrobianos e histórico de venda em uma farmácia comunitária do estado do Rio de Janeiro.

\subsection{Antibióticos e Resistência Bacteriana}

O conhecimento dos princípios gerais que norteiam o uso de antibióticos, assim como das propriedades e características básicas dos mesmos disponíveis são essenciais para uma escolha terapêutica adequada (KATZUNG, 2010).

Podem existir diferentes classificações, mas a que se baseia em parte na estrutura química do antibiótico e no efeito na região da bactéria pode ser interessante para os pacientes e os profissionais da área de saúde como médicos, farmacêuticos e enfermeiros (BARROS, 2008) (Quadro 1).

Um dos maiores problemas da medicina moderna é o uso indiscriminado dos antibióticos, o que tem levado ao surgimento de bactérias resistentes aos mesmos. Quando os primeiros antibióticos começaram a ser comercializados, tinha-se a ideia de que as doenças infecciosas estavam com os dias contados e que era apenas uma questão de tempo para que as infecções bacterianas fossem erradicadas. Porém, conforme o uso de novos antibióticos foi se tornando mais disseminados, cepas resistentes de bactérias foram surgindo e multiplicando, criam-se, assim, um ciclo vicioso que persiste até os dias atuais. Quanto mais antibióticos são criados, mais bactérias resistentes surgem (BRITO \& CORDEIRO, 2012; TAVARES, 2009). 


\begin{tabular}{|c|c|c|c|c|c|}
\hline $\begin{array}{c}\text { Classe de } \\
\text { Antibiótico }\end{array}$ & $\begin{array}{l}\text { Principais } \\
\text { moléculas - } \\
\text { princípios } \\
\text { ativos da } \\
\text { família }\end{array}$ & $\begin{array}{c}\text { Classe de } \\
\text { Antibiótico }\end{array}$ & $\begin{array}{l}\text { Principais } \\
\text { moléculas - } \\
\text { princípios } \\
\text { ativos da } \\
\text { família }\end{array}$ & $\begin{array}{c}\text { Classe de } \\
\text { Antibiótico }\end{array}$ & $\begin{array}{l}\text { Principais } \\
\text { moléculas - } \\
\text { princípios } \\
\text { ativos da } \\
\text { família }\end{array}$ \\
\hline \multirow{13}{*}{ Cefalosporinas } & $1^{\mathbf{a}}$ geração & \multirow{4}{*}{ Macrolídeos } & Azitromicina & \multirow{6}{*}{$\begin{array}{c}\text { Outros } \\
\text { (diversos) }\end{array}$} & Fosfomicina \\
\hline & -Cefadroxila & & Eritromicina & & Clindamicina \\
\hline & -Cefazolina & & Roxitromicina & & Tiamfenicol \\
\hline & -Cefalexina & & Claritromixina & & Imipenem \\
\hline & $2^{a}$ geração & \multirow{5}{*}{$\begin{array}{c}\text { (Fluoro) } \\
\text { quinolonas }\end{array}$} & Ciprofloxacina & & Metronidazol \\
\hline & -Cefaclor & & Levofloxacina & & Vancomicina \\
\hline & -Cefuroxima & & Moxifloxacina & \multirow{5}{*}{$\begin{array}{l}\text { Aminosídeos } \\
\text { (aminoglicosí } \\
\text { deos) }\end{array}$} & Neomicina \\
\hline & $3^{\text {a }}$ geração & & Norfloxacina & & Tobramicina \\
\hline & -Cefixima & & Ofloxacina & & Amicacina \\
\hline & -Cefpodoxima & \multirow{3}{*}{ Sulfamidas } & Sulfametozaxol & & Estreptomicina \\
\hline & -Cefotaxima & & Trimetoprima & & Gentamicina \\
\hline & -Ceftazidima & & Sulfazalazina & \multirow{5}{*}{ Penicilinas } & $\begin{array}{l}\text { Amoxicilina + } \\
\text { ác. clavulânico }\end{array}$ \\
\hline & -Ceftriaxona & \multirow{4}{*}{ Antituberculosos } & Etambutol & & Ampicilina \\
\hline \multirow{3}{*}{ Tetraciclinas } & Doxiclina & & Isoniazida & & Penicilina $\mathrm{G}$ \\
\hline & Minociclina & & Pirazinamida & & Penicilina V \\
\hline & Tetraciclina & & Rifampicina & & Piperacilina \\
\hline
\end{tabular}

Quadro 1: classe dos antibióticos adaptado de Rang et al. (2012).

Em uma infecção bacteriana, geralmente essas bactérias são da mesma espécie, contudo não são exatamente iguais; não são clones. Nesse caso, é de determinante preferência usar um antibiótico que seja eficaz contra a maioria das bactérias presentes. Nem sempre o antibiótico mata $100 \%$ das bactérias. O que acontece é que se reduz o número de bactérias para $5 \%$ a $10 \%$, a infecção desaparece porque o sistema imune é capaz de controlar o que sobrou (FIOL et al, 2011).

Porém, muitas vezes o nosso organismo não consegue se livrar completamente dessas bactérias, permitindo que as mesmas se reproduzam e causem uma nova infecção, agora composta apenas por bactérias resistentes ao antibiótico escolhido inicialmente (ROCHA et al, 2011).

Esse é um exemplo simplificado do que ocorre na realidade. Geralmente são necessários alguns cursos repetidos do mesmo antibiótico, ao longo de meses ou anos, para que surjam bactérias resistentes. Esse processo é nada mais do que a seleção natural, onde os mais fortes sobrevivem e passam seus genes para seus descendentes (CLARK et al, 2010).

Algumas espécies de bactérias são propensas a criar resistência, assim como alguns antibióticos causam resistência com mais facilidade, alguns fatos, entretanto, favorecem o surgimento mais rápido de cepas resistentes. O principal é a interrupção precoce do tratamento (KATZUNG, 2010).

Outro fator importante é o uso indiscriminado de antibióticos. Muitas das infecções que temos são causadas por bactérias que vivem naturalmente no nosso corpo, controladas pelo nosso sistema imune, apenas à espera de uma queda nas defesas para atacarem. Se o paciente usa muitos antibióticos sem necessidade, por exemplo, para tratar infecções virais, ele estará previamente selecionado as bactérias mais resistentes, e, futuramente, quando houver uma real infecção bacteriana, esta será causada já por bactérias resistentes (CRF-ES, 2010).

\subsection{Resolução De Diretoria Colegiada $N^{o} 44 / 2010$}

A ANVISA regulamentou no dia 28 de outubro de 2010 a RDC 44, que tem como objetivo diminuir a resistência microbiana, no qual o uso abusivo e indiscriminado de antibióticos é a principal causa. 
As drogarias e farmácias privadas tem como obrigatoriedade a devida inclusão no módulo I do Sistema Nacional de Gerenciamento de Produtos Controlados (SNGPC), e passando a fazer a escrituração a partir de 25 de abril de 2011, essa escrituração tendo como base a substância e medicamentos antimicrobiano isolado ou em associações deve ser atualizada no prazo máximo de 7 dias (CRF-MT, 2010). A exigência da escrituração foi prorrogada por mais 180 dias pela RDC 20/2011 (BRASIL, 2011).

As farmácias públicas, farmácias hospitalares, distribuidoras e indústrias de medicamentos que não foram integrados ao módulo I do SNGPC devem fazer a escrituração no mesmo prazo das farmácias e drogarias privadas, em um livro de registro específico para antimicrobianos onde deverá ser feito a caneta de forma legível, sem rasuras ou emendas e assinada pelo responsável técnico, ou em um sistema informatizado autorizado pela vigilância sanitária local ou estadual (BRASIL, 2010).

\section{Metodologia}

Foi realizado um estudo retrospectivo quantitativo e documental com o intuito de analisar o perfil de prescrições, retenções de receituário e dispensação de fármacos antimicrobianos.

A primeira etapa da pesquisa avaliou a quantidade de caixas de antimicrobianos dispensadas, sendo os antimicrobianos divididos por classes. A pesquisa teve como data inicial o dia 26 de outubro de 2009, um ano antes da promulgação da RDC 44/2010. A segunda etapa analisou-se a quantidade dispensada no ano subsequente à promulgação da mesma e um ano após à necessidade da escrituração.

O estudo foi realizado através da análise de um banco de dados da farmácia, com o suporte de dados computadorizados pelo programa de gerenciamento para obtenção do perfil de dispensação dos antimicrobianos.

Em seguida foi realizado um estudo documental, no qual, coletou-se dados referentes à retenção de receitas nos dois anos que sucederam a resolução, comparando com a dispensação dos antimicrobianos nesse período.

\section{Resultados e Discussão}

Tendo como base um ano antes da promulgação da RDC 44/2010, pode-se observar que o perfil de dispensação dos antimicrobianos diminuiu, sendo isso um dos principais objetivos da resolução, que é conscientizar os profissionais da área de saúde a diminuir a dispensação de antimicrobianos para que assim, possa frear o avanço da resistência bacteriana. A tabela 1 mostra o perfil de dispensação no ano que antecede a resolução e nos dois anos que se sucederam, como resultado, apresentou uma diminuição gradual na dispensação dos mesmos. 
Tabela 1: Perfil de dispensação de antimicrobianos por classe, um ano antes e nos dois anos subsequentes à promulgação da RDC 44/2010.

\begin{tabular}{|c|c|c|c|c|c|c|}
\hline \multirow[b]{2}{*}{$\begin{array}{c}\text { Classe de } \\
\text { antibióticos }\end{array}$} & \multirow{2}{*}{$\begin{array}{c}\text { 29/10/2009 a } \\
\text { 28/10/2010 } \\
\text { Caixas } \\
\text { dispensadas }\end{array}$} & \multicolumn{2}{|c|}{$29 / 10 / 2010$ a $28 / 10 / 2011$} & \multicolumn{3}{|c|}{$29 / 10 / 2011$ a $28 / 10 / 2012$} \\
\hline & & $\begin{array}{c}\text { Caixas } \\
\text { dispensadas }\end{array}$ & $\begin{array}{c}\text { Proporção } \\
\text { em relação } \\
\text { ao período } \\
\text { anterior }\end{array}$ & $\begin{array}{c}\text { Caixas } \\
\text { dispensadas }\end{array}$ & $\begin{array}{c}\text { Proporção } \\
\text { em relação } \\
\text { ao período } \\
\text { anterior }\end{array}$ & $\begin{array}{c}\text { Proporção } \\
\text { em relação a } \\
\text { antes da } \\
\text { promulgação }\end{array}$ \\
\hline Aminosídeos & 77 & 59 & $-23,4 \%$ & 48 & $-18,6 \%$ & $-37,7 \%$ \\
\hline $\begin{array}{c}\text { Cefalosporinas } 1^{\mathrm{a}} \\
\text { geração }\end{array}$ & 293 & 231 & $-21,2 \%$ & 141 & $-39,0 \%$ & $-51,9 \%$ \\
\hline $\begin{array}{c}\text { Cefalosporinas } 2^{\mathrm{a}} \\
\text { geração }\end{array}$ & 44 & 33 & $-25,0 \%$ & 20 & $-39,4 \%$ & $-54,5 \%$ \\
\hline $\begin{array}{c}\text { Cefalosporinas } 3^{\mathrm{a}} \\
\text { geração }\end{array}$ & 30 & 18 & $-40,0 \%$ & 12 & $-33,3 \%$ & $-60,0 \%$ \\
\hline Diversos & 261 & 237 & $-9,2 \%$ & 168 & $-29,1 \%$ & $-35,6 \%$ \\
\hline Macrolídeos & 299 & 238 & $-20,4 \%$ & 124 & $-47,9 \%$ & $-58,5 \%$ \\
\hline Penicilínicos & 254 & 170 & $-33,1 \%$ & 140 & $-17,6 \%$ & $-44,9 \%$ \\
\hline Quinolonas & 146 & 109 & $-25,3 \%$ & 95 & $-12,8 \%$ & $-34,9 \%$ \\
\hline Sulfamidas & 121 & 93 & $-23,1 \%$ & 78 & $-16,1 \%$ & $-35,5 \%$ \\
\hline Tetraciclinas & 44 & 30 & $-31,8 \%$ & 23 & $-23,3 \%$ & $-47,7 \%$ \\
\hline
\end{tabular}

Analisando a classe mais dispensada no período, os macrolídeos, houve uma diminuição na dispensação de 299 caixas nos anos que precedeu a resolução para apenas 124 caixas no período após a necessidade da escrituração, sendo que, em relação houve uma redução de 47,9\% na quantidade de caixas dispensadas no período após a obrigatoriedade da escrituração e o primeiro ano após a promulgação, enquanto não era obrigatório a escrituração. A figura 1 demonstra a queda na dispensação.

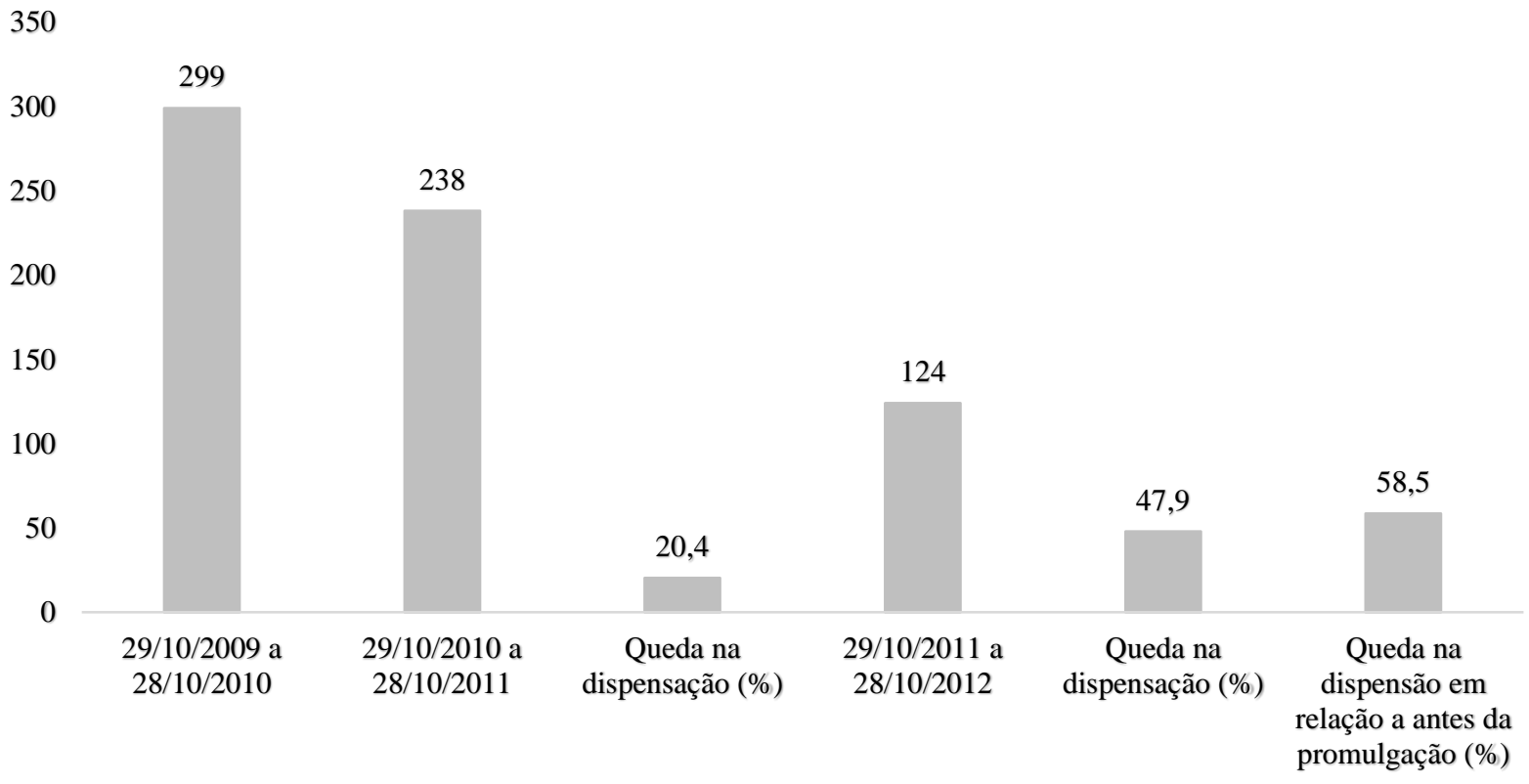

Figura 1: Perfil de dispensação de macrolídeos no período de 29/10/2009 a 28/10/2012.

Durante o estudo, constatou-se que o antimicrobiano mais dispensado no período analisado foi a azitromicina, da classe dos macrolídeos (621 caixas), seguido pela cefalexina (603 caixas). 
A figura 2 mostra o perfil dos antimicrobianos mais dispensados no período entre 29/10/2009 a 28/10/2012.

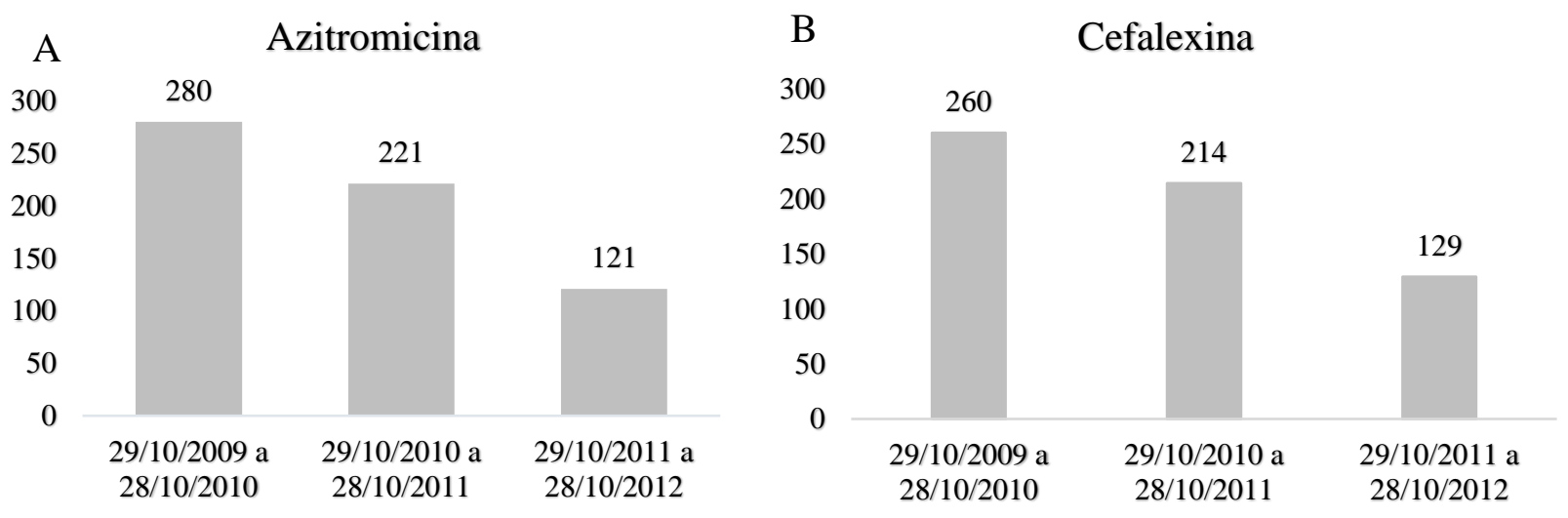

Figura 2: Perfil de dispensação da azitromicina (A) e da cefalexina (B) no período entre 29/10/2009 a 28/10/2012.

Constatou-se também que não só a dispensação de antimicrobianos foi afetada, é importante observar a alteração no perfil de retenção dos receituários, após a regulamentação da RDC 44/2010. Como todos os fármacos antimicrobianos que fossem dispensados pelas farmácias e drogarias deveriam ter a receita retida, houve também um aumento na quantidade de prescrições. A figura 3 demonstra o perfil de retenção das receitas em uma farmácia comunitária no ano após as promulgações da resolução.

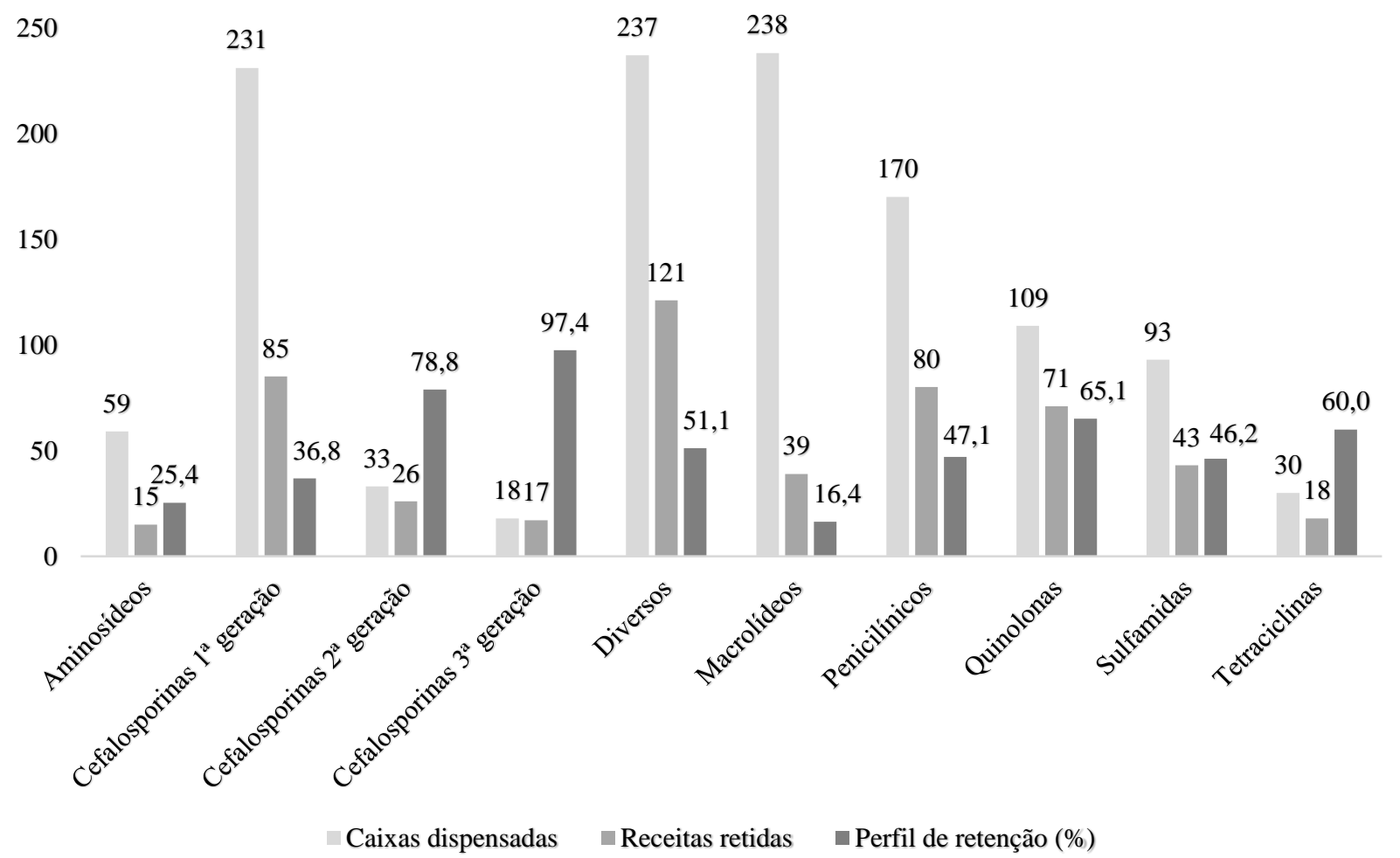

Figura 3: Perfil de retenção de receitas no período de 29/10/2010 a 28/10/2011.

No primeiro ano que a RDC 44/2010 entrou em vigor, pode-se observar uma pequena quantidade de receitas retidas em comparação com a quantidade de caixas antibióticos dispensados, percebe-se que em nenhuma das classes analisadas a quantidade de caixas 
dispensadas em relação à retenção da receita. A classe que houve maior proporção de retenções foi a de cefalosporinas de $3^{a}$ geração $(97,4 \%)$, enquanto que os macrolídeos tiveram a menor proporção $(16,4 \%)$, apesar de ser o antimicrobiano com maior número de caixas dispensadas, o que demonstra a existência da automedicação e o não atendimento à legislação vigente que impõe a retenção do receituário antes da dispensação (BRASIL, 2010).

Para fazer uma comparação sobre o perfil de retenção das receitas, a figura 4 e 5 apresentam as retenções no período entre 29/10/2011 a 28/10/2012, período que sucedeu à obrigatoriedade de registro no SNGPC, no qual pode-se observar que proporção de retenção aumentou em comparação ao período anterior. Os macrolídeos apresentaram um aumento de $233 \%$ na quantidade de prescrições retida, apesar da diminuição de 45,3\% do número de caixas dispensadas, porém, as classes tiveram o percentual de retenção inferior ao de caixas dispensadas, demonstrando que ainda a farmácia não atendia a legislação vigente.

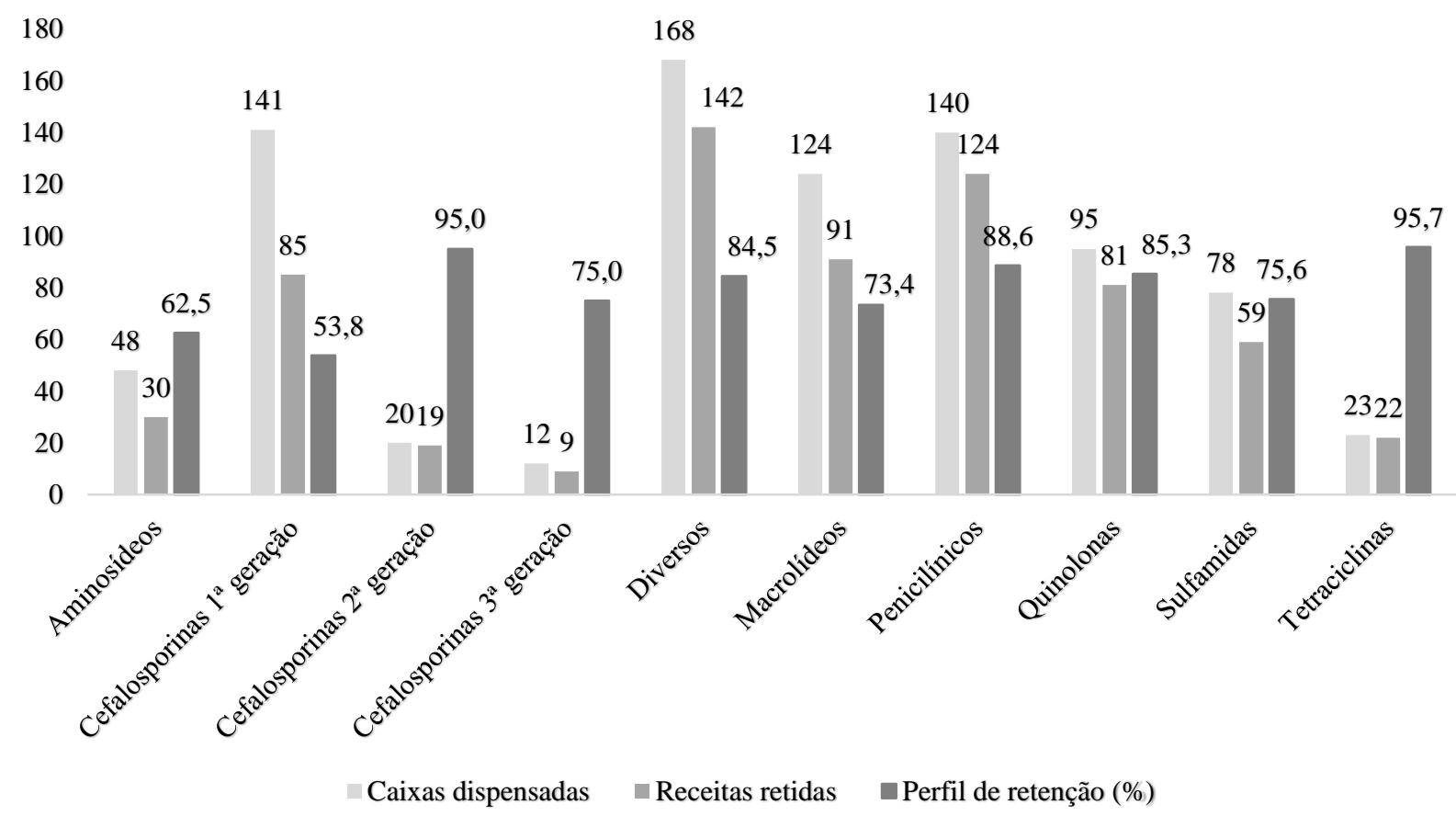

Figura 4: Perfil de retenção de receitas no período de 29/10/2011 a 28/10/2012. 


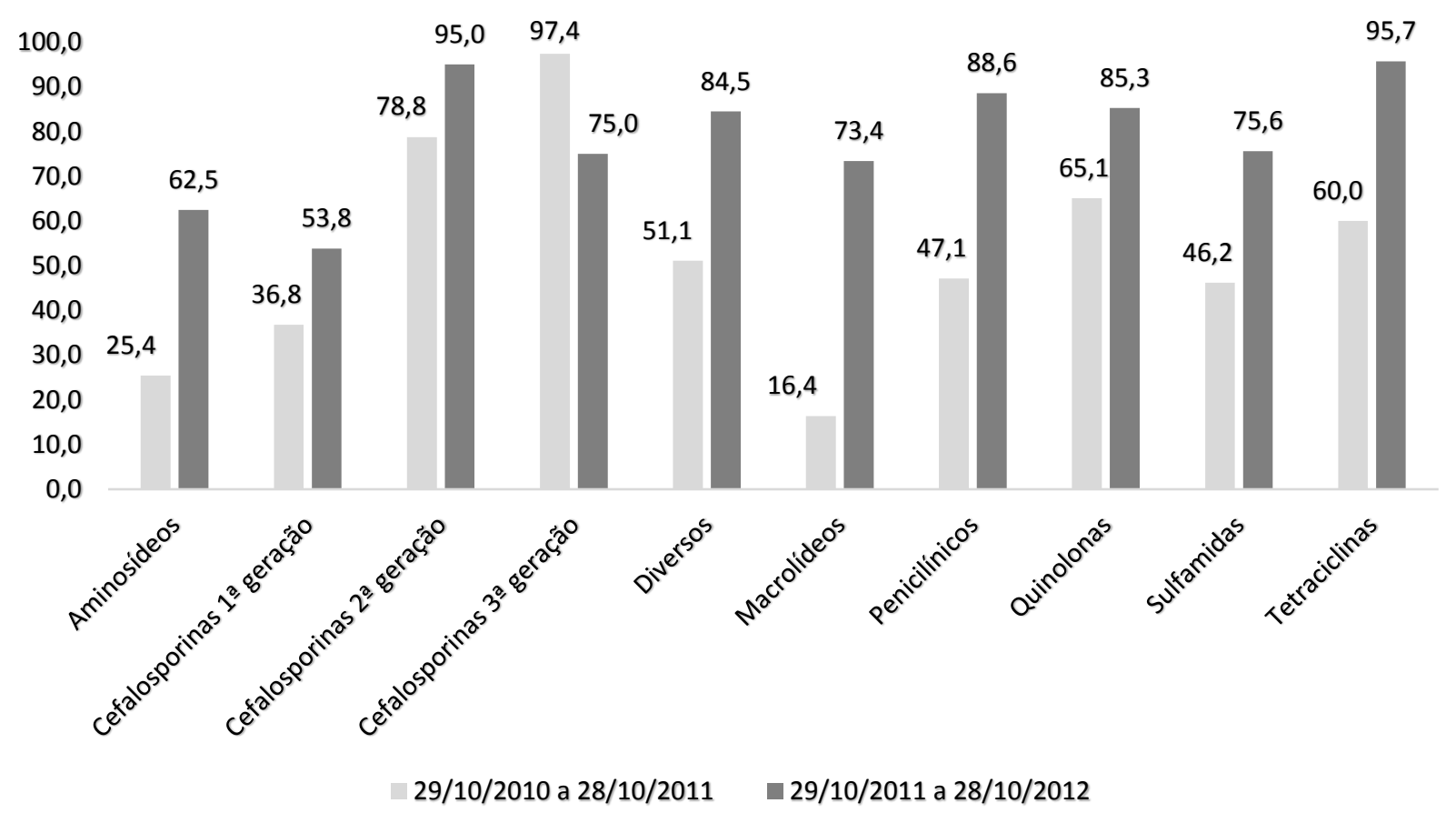

Figura 5: Perfil de retenção, em termos percentuais, comparado nos períodos após a promulgação da RDC 44/2010.

\section{Conclusão}

O estudo demonstrou que a RDC 44/2010 não está sendo cumprida pela drogaria, na qual ainda há antimicrobianos sendo dispensados de forma irregular, no entanto, pode-se afirmar que, a cada ano a dispensação irracional vem diminuendo. Por outro lado, as retenções de receituário estão aumentando, segundo os dados levantados.

No primeiro ano após a promulgação da RDC 44/2010 houve uma diminuição de $22,4 \%$ da dispensação de antimicrobianos em relação ao ano que precedeu à resolução, e, de 30,3\% no período seguinte, em relação ao primeiro ano após a resolução, coincidindo com a necessidade do registro das receitas no SNGPC. O déficit geral é de 45,9\% na quantidade de caixas dispensadas.

O antimicrobiano mais dispensado foi o macrolídeo (azitromicina) com um total de 621 caixas, tendo um decréscimo de 56,8\% nas vendas, seguido pela cefalexina, com 603 caixas dispensadas e decréscimo de $50,4 \%$.

Um destaque importante deve-se dar ao fato que, nas caixas de antimicrobianos, onde se localiza a tarja vermelha, antes da regulamentação da RDC 44/2010 vinha impresso os dizeres: "VENDA SOB PRESCRIÇÃO MÉDICA" e com isso, após a promulgação da resolução, muitas caixas ainda foram dispensadas sem a devida retenção, pois estavam estocadas na farmácia ou nas distribuidoras, que por possuir grande estoque, seguiu vendendo desse mesmo lote, após a validação da resolução. As caixas de antimicrobianos, onde se localiza a tarja vermelha, vem escrito agora "VENDA SOB PRESCRIÇÃO MÉDICA, SÓ PODE SER VENDIDO COM RETENÇÃO DE RECEITA”, e com isso, a retenção das receitas acabou sendo mais rigorosa, pode-se observar que o terceiro ano do estudo, 29/10/2001 a 28/10/2012, quando as caixas de antimicrobianos já estavam impressas com os novos dizeres, todas as classes de antimicrobianos obtiveram uma redução em seu perfil de dispensação e no número de retenções de receitas.

A população está mais alerta ao uso de antimicrobianos, principalmente pelo fato da resistência bacteriana, entretanto, pode-se observar que, ainda conseguem adquirir esses medicamentos sem a devida retenção da receita, talvez pelo fato da falta de conhecimento ou da falta de fiscalização sanitária no país. 
O profissional farmacêutico deve ampliar sua participação na farmácia comunitária, pois é exclusive responsabilidade sobre a dispensação dos antimicrobianos, e também, o farmacêutico tem o papel fundamental de orientar a população sobre assuntos diversos e principalmente sobre cuidados com os medicamentos, interações medicamentosas e uso racional dos antimicrobianos.

O treinamento dos profissionais da saúde, desde os preceptores aos dispensadores é muito importante para a multiplicação e fiscalização do cumprimento da resolução e no intuito de englobar toda a população a fim de garantir uma correta farmacoterapia, buscando assim, diminuir a resistência bacteriana.

O cumprimento da RDC 44/2010 é indispensável para o controle de fármacos antimicrobianos como também no controle da resistência bacteriana e tem alta contribuição para a prevenção da automedicação.

\section{Referências}

BARROS, E. Antimicrobianos: Consulta rápida. 4. ed. Porto Alegre: Artmed, 2008.

BRASIL, ANVISA. Especial RDC 44/2010 - Antibióticos. Disponível em: $<$ http://pfarma.com.br/noticia-setor-farmaceutico/legislacao-farmaceutica/387-rdc-44-2010antibioticos.html>. Acesso em 02 mar. 2017.

BRASIL. Diário Oficial da União. Resolução - RDC No 20 de 09 de maio de 2011. DOU n ${ }^{\circ} 87$, segunda-feira, 9 de maio de 2011, Seção 1, p. 39 a 41. Disponível em: <http://www.anvisa.gov.br/divulga/noticias/2009/pdf/180809_rdc_44.pdf>. Acesso em 23 fev. 2017.

BRASIL. Diário Oficial da União. Resolução - RDC No 44 de 26 de outubro de 2010. DOU n 207, quinta-feira, 28 de outubro de 2010, Seção 1, p. 76 e 77. Disponível em: <http://www.anvisa.gov.br/divulga/noticias/2009/pdf/180809_rdc_44.pdf>. Acesso em 23 fev. 2017.

BRITO, Monique Araújo de; CORDEIRO, Benedito Carlos. Necessidade de novos antibióticos. Jornal Brasileiro de Patologia e Medicina Laboratorial, Rio de Janeiro, v. 48, n. 4, p.247-249, ago. 2012. Disponível em: <http://www.scielo.br/pdf/jbpml/v48n4/v48n4a02.pdf>. Acesso em: 3 mar. 2017.

CLARK, Michelle A. et al. Farmacologia Ilustrada. 4. ed. Porto Alegre: Artmed, 2010

CRF-ES, Conselho Regional de Farmácia do Espírito Santo. Uso excessivo de antibióticos gera bactérias multirresistentes. Disponível em: <http://www.crfes.org.br/noticias_20102010_2.html>. Acesso em 02 mar. 2017.

CRF-MT, Conselho Regional de Farmácia do Mato Grosso. Fiscalização. RDC 44/2010 controle especial de antimicrobianos. Disponível em: <http://www.crfmt.org.br/materias.php?subcategoriaId=4\&id=767>. Acesso em 02 mar. 2017.

FIOL, Fernando de Sá del et al. Perfil de prescrições e uso de antibióticos em infecções comunitárias. Revista da Sociedade Brasileira de Medicina Tropical, Uberaba, v. 1, n. 43, p.6872, jan. 2010. Disponível em: <http://www.scielo.br/pdf/rsbmt/v43n1/a15v43n1>. Acesso em: 01 mar. 2017. 
KATZUNG, Bertram G.; MASTERS, Susan B.; TREVOR, Anthony J. Farmacologia Básica \& Clínica. 12. ed. Rio de Janeiro: Mcgraw-hill Interamericana, 2014.

PINHEIRO, Pedro. Antibióticos: O que são, tipos, resistência e indicações. 2011. Disponível em: <http://www.mdsaude.com/2011/02/antibioticos.html>. Acesso em: 03 mar. 2017.

RANG, H. P. et al. Farmacologia. 7. ed. Rio de Janeiro: Elsevier, 2012.

ROCHA, Diego Pessoa et al. Coordenação De Metais A Antibióticos Como Uma Estratégia De Combate À Resistência Bacteriana. Química Nova, São Paulo, v. 34, n. 1, p.111-118, jan. 2011. Disponível em: <http://quimicanova.sbq.org.br/imagebank/pdf/Vol34No1_111_21RV10053.pdf>. Acesso em: 02 mar. 2017.

TAVARES, Walter. Antibióticos e quimioterápicos para uso clínico. 2. ed. São Paulo: Atheneu, 2009. 